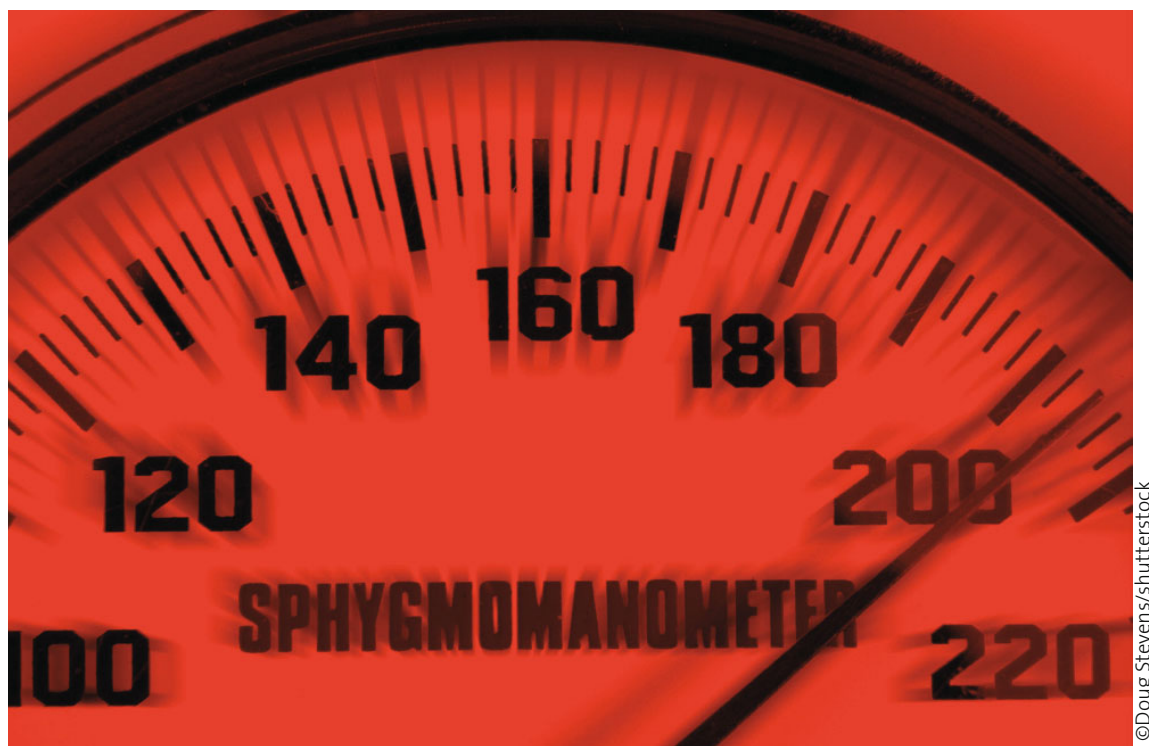

Bei solchen RR-Werten sollte eine sofortige Kontrollmessung erfolgen.

\section{Die häufigsten Fehler in der Therapie der schweren Hypertonie}

Keine Kontrollmessung, keine adäquate Intensivierung der Therapie, keine Überweisung zum Spezialisten und kein zeitnaher Kontrolltermin: Bei Patienten, bei denen ein deutlich erhöhter Blutdruck gemessen wurde, läuft noch immer viel falsch.

— Zwischen Mitte 1999 und Ende 2000 kamen 59207 Patienten (97\% Männer) regelmäßig, mindestens aber dreimal in die Ambulanz einer Veterans-Administration-Klinik. 13735 (23\%) von ihnen hatten bei mindestens einem, 5494 bei mehreren Besuchen eine schwere Hypertonie mit Werten $<180 / 110 \mathrm{mmHg}$. Diese Gruppe war älter und hatte häufiger Begleiterkrankungen als das Gesamtkollektiv.

Die weitere Analyse deckte gravierende Defizite in der Betreuung dieser aber $73 \%$ weiterhin einen erhöhten Blutdruck.

Bei schwerer Hypertonie wurden zwar im Lauf der Studie mehr Antihypertensiva verordnet, aber am Studienende hatten Patienten mit unkontrollierter Hypertonie weniger Blutdrucksenker und seltener ein leitliniengerechtes Behandlungsschema als Hypertoniker mit Normalwerten.

\section{Kommentar}

Die Autoren beanspruchen, die umfangreichste Studie zur Häufigkeit und zum Behandlungsmodus von Patienten mit schwerer Hypertonie vorgelegt zu haben. Seit 2000 mag sich zwar der Behandlungsstatus gebessert haben, jedoch hat sich die Häufigkeit der Hypertonie in den VA-Kliniken in der Zwischenzeit von 37 auf 55-60\% erhöht, sodass die absolute Zahl unzureichend behandelter Hypertoniker gestiegen sein dürfte.

Die Analyse deckt gravierende Defizite in der Betreuung der Patienten mit schwerer Hypertonie auf: zu späte Kontrolltermine, unzureichende Intensivierung und inadäquate Auswahl der Antihypertensiva und zu seltene Überweisung zum Spezialisten. Ein weiterer Mangel: Bei einem Blutdruck $<180 / 110 \mathrm{mmHg}$ erfolgte nur bei $13 \%$ der Patienten eine sofortige Kontrollmessung. Da Folgemessungen meistens zu niedrigeren Werten führen, hätte diese Maßnahme höchstwahrscheinlich die Zahl der schweren Hypertoniker vermindert, während durch eine Bestätigung der Werte die gefährdeten Patienten zuverlässig erkannt worden wären.

H. HolzG ReVe = enten wurde die Therapie intensiviert, nur 20\% wurden in eine Spezialabteilung wie Diabetologie, Nephrologie oder Kardiologie überwiesen. Beim letzten Besuch in der Beobachtungsperiode hatten nur $24 \%$ einen normalen,
- A. M. Borzecki et al.

The epidemiology and management of severe hypertention. J. Hum. Hypertens. 24 (2010) 9-18 